\title{
A CRÔNICA BRASILEIRA TECIDA PELA HISTÓRIA, PELO JORNALISMO E PELA LITERATURA*
}

\author{
Silvânia Siebert** \\ Universidade do Sul de Santa Catarina \\ Tubarão, Santa Catarina, Brasil
}

\begin{abstract}
Resumo: Neste texto, buscamos analisar como o gênero crônica histórica passa a funcionar como crônica brasileira, a partir do século XIX. Para isso, observamos a cadeia de sentidos que se constrói com o gênero ao longo de seu percurso discursivo, enfocando principalmente a trama discursiva dos discursos da História, do Jornalismo e da Literatura. A perspectiva teórica que embasa esta reflexão parte, principalmente, das leituras de Bakhtin (2003), Grillo (2006) e Machado (2005) sobre gêneros discursivos, e de Alencar (2003), Braga (2011), Coutinho (2003), Candido (1992) Meyer (1992), Santos (2005), entre outros, sobre o gênero crônica e seu funcionamento.
\end{abstract}

Palavras-chave: Crônica. Gênero. Enunciado. História. Jornalismo. Literatura.

1 INTRODUÇÃO

Neste artigo, buscamos analisar como se dá a trama discursiva entre as diferentes esferas/campos ligadas à História, ao Jornalismo e à Literatura que, articuladas ou engendradas, permitem a realização do gênero "crônica brasileira". Para Grillo, "A noção de esfera permeia a caracterização do enunciado e dos seus tipos estáveis, os gêneros, no que diz respeito ao seu tema, à sua relação com elos precedentes (enunciados anteriores) e com os elos subsequentes (a atitude responsiva de seus enunciadores)" (GRILLO, 2006, p. 146).

Com este gesto de leitura buscamos delimitar nosso campo de olhar a partir da observação do percurso semântico da crônica, dando ênfase ao funcionamento do gênero crônica brasileira, que se realiza a partir do século XIX. Neste período ocorrem mudanças profundas no campo político, econômico, social e cultural no Brasil, o que, em nosso entendimento, está refletido no gênero crônica brasileira. Segundo Bakhtin (2003), a análise dos gêneros nos permite observar o funcionamento do enunciado como fato histórico/cultural, na busca de compreendermos como o enunciado se realiza na língua e vice-versa. Ao analisarmos o enunciado sob a perspectiva do dialogismo estaremos observando mais o contexto comunicativo e a cultura do que propriamente a

\footnotetext{
* Este artigo remete a um tópico de nossa tese de doutorado Crônicas em antologias, suas adaptações audiovisuais e os sentidos: o gênero na formação intercultural discursiva em comunicação social, defendida no IEL/Unicamp, em 2012. Foi apresentado no Primeiro Seminário Nacional Discurso, Cultura e Midia, realizado na Unisul em 2012.

** Doutora em Linguística Aplicada pela UNICAMP. Professora do Programa de Pós-graduação em Ciências da Linguagem da Unisul. Email: silvania.siebert@unisul.br.
} 
palavra. De acordo com Machado (2005, p. 159), "o gênero, na teoria do dialogismo, está inserido na cultura, em relação à qual se manifesta como 'memória criativa' onde estão depositadas não só as grandes conquistas das civilizações, como também as descobertas significativas sobre os homens e suas ações no tempo e no espaço". A crônica, nesse sentido, é um gênero privilegiado, pois nos permite compreender a relação entre a história da sociedade e a história da linguagem. Para a análise do gênero discursivo, Bakhtin (2003) sugere conhecer a história do gênero, procedimento que realizaremos nas seções intituladas: Crônica histórica e Crônica brasileira; Bakhtin também propõe classificar o gênero como primário, quando constituído por determinados tipos de diálogos orais, ou como gênero secundário, quando formado por textos literários, publicísticos, científicos, etc.; este procedimento será realizado na seção: A crônica - suas condições de produção e circulação. Esta classificação será realizada a partir da observação dos enunciados recortados de pesquisadores que trabalham no estudo da crônica e de cronistas, que em suas produções buscavam definir o gênero.

\section{CRÔNICA HISTÓRICA}

O gênero possui uma relação estreita com o tempo, expressa em sua etimologia, pois a palavra 'crônica' tem origem em Cronos, o tempo. Na mitologia grega, Cronos ocupa o lugar de vilão: ele trai os pais Urano e Gaia e se casa com a irmã Reia, a fim de ocupar o trono no Olimpo. Urano e Gaia rogam-lhe uma praga, segundo a qual seus próprios filhos o derrotariam. Para que o desígnio não se cumpra, Cronos devora um a um seus próprios filhos ao nascerem. Reia, porém, consegue enganar Cronos e, ao dar à luz, dá-lhe de comer uma pedra. O filho poupado da morte é Zeus, que, tempos depois, oferece uma droga ao pai e o faz vomitar todos os filhos devorados, os quais, unidos, derrotam o pai após uma sangrenta guerra (BENDER; LAURITO, 1993). A passagem mitológica de Cronos mostra a relação etimológica do termo 'cronos' com o tempo, que pretende ser imutável, infalível, mas, independentemente de qualquer vontade, transcorre e muda sem que deuses ou humanos possam retê-lo. O tempo é senhor de "cronos", e a partir dessa relação é cunhado o termo grego chronikós, o termo em latim chronicus e o português crônica (BENDER; LAURITO, 1993). O tempo relatado da liturgia, o tempo cronológico linear e o tempo escatológico (LE GOFF, 2003) serviram de referência aos cronistas que relatavam os feitos históricos. Essa importância dada ao tempo nos leva até Platão, que se dedicou ao seu estudo e o definia como a imagem móvel da eternidade. Também Aristóteles o conceituava como "o número de movimento segundo o antes e o depois". Ambos os filósofos relacionavam a ideia de tempo à de movimento, ao que se passa entre um período, um intervalo.

$\mathrm{Na}$ crônica, permanece a ideia de registrar o ocorrido em um intervalo de tempo, de servir de memória do que já passou, e tal característica marca os textos produzidos ao longo da história. Na Idade Média, os espanhóis e os portugueses, no período das circunavegações, faziam uso do gênero para relatarem os acontecimentos durante as viagens; assim, as crônicas serviam de registro para os descobrimentos de outras terras no Novo Mundo. A crônica funcionava como um documento que estaria ligado ao 
relato cronológico dos fatos e, segundo Coutinho (1964), aos fatos bem-sucedidos em qualquer lugar. Desse modo, poderemos tomar como exemplos a referência dada por Coutinho da Crônica Geral de Espanha, publicada em 1344, e o registro de Pero Vaz de Caminha sobre o descobrimento do Brasil, marcando a relação do cronista com seu interlocutor: "Tome Vossa Alteza, porém, minha ignorância por boa vontade, e creia bem por certo que, para aformosear nem afear, não porei aqui mais do que aquilo que vi e me pareceu". O registro do achamento da Terra de Vera Cruz assegura à carta a posição de crônica histórica (CASTRO, 2007, p. 36). Segundo Melo (2002, p. 140): “A crônica histórica assume, portanto, o caráter de relato circunstanciado sobre feitos, cenários e personagens, a partir da observação do próprio narrador ou tomando como fonte de referência as informações coligidas junto a protagonistas ou testemunhas oculares".

Mas isto não significa dizer que seja uma crônica brasileira, termo que iremos adotar para as crônicas publicadas nos folhetins brasileiros. No início do século XVI, o funcionamento da crônica tem relação estreita com a narrativa de viagem, com os testemunhos das conquistas "além-mar"; nesse caso, os registros traziam a descrição pormenorizada do cenário e dos sujeitos encontrados em suas viagens. E o cronista se coloca na posição de um observador da cena histórica, conforme atesta Sá (1997, p. 6):

\begin{abstract}
a observação direta é o ponto de partida para que o narrador possa registrar os fatos de tal maneira que mesmo os mais efêmeros ganhem uma certa concretude. Essa concretude lhes assegura a permanência, impedindo que caiam no esquecimento, e lembra aos leitores que a realidade - conforme a conhecemos, ou como é criada pela arte - é feita de pequenos lances. Estabelecendo essa estratégia, Caminha estabeleceu também o princípio básico da crônica: registrar o circunstancial.
\end{abstract}

Se o circunstancial está presente no relato de Caminha, a sua subserviência também, marcando uma relação assimétrica entre autor e leitor. Esta posição, por sua vez, não é adotada pelos cronistas do século XIX, que falam diretamente com seu interlocutor, e desta forma estabelecem uma relação diferenciada, que constitui um dos fatores determinantes para a realização do gênero crônica brasileira, como veremos na próxima seção.

\title{
3 CRÔNICA BRASILEIRA
}

Até o início do século XIX, a crônica funcionava como relato histórico, e o destaque era dado aos acontecimentos realizados pelos conquistadores, os colonizadores. Era uma reconstituição, pela escrita, das conquistas à corte ${ }^{1}$. Porém, ao ter contato com as Américas, ou melhor, com o Brasil, o termo passou a funcionar de outra maneira: “a palavra foi ganhando roupagem semântica diferente. 'Crônica' e 'cronista' passaram a ser usados com o sentido atualmente generalizado na literatura: é um gênero específico, estritamente ligado ao jornalismo" (COUTINHO, 2003, p. 120121).

\footnotetext{
${ }^{1}$ Artistas como Debret pintavam as paisagens brasileiras dando caráter documental às artes plásticas.
} 
A mudança semântica começa a ser percebida pela entrada de outro sujeito nesse discurso, o narrador nativo, o brasileiro, a partir da chegada da família real ao Brasil em 1808 e da autorização para a publicação de jornais em terras brasileiras no mesmo ano. Até aqui, quem falava, escrevia e publicava pelo brasileiro era o colonizador, o europeu. Dessa maneira, a Imprensa Brasileira ganha novos escritores, além de novas formas de produção e circulação (o que não a impede de continuar recebendo influências das publicações portuguesas, inglesas e principalmente francesas). Segundo Meyer, sob a influência dos folhetins franceses, autores brasileiros redigem a crônica à brasileira, publicando-a no rodapé do folhetim. "Tem uma finalidade precisa: é um espaço vazio destinado ao entretenimento. E já se pode dizer tudo o que haverá de constituir a matéria e o modo da crônica à brasileira" (MEYER, 1992, p. 96).

Com essas condições de produção (PÊCHEUX, 1997), a Imprensa Nacional começa a funcionar e a circular, permitindo a fabricação de um jornal brasileiro, que leva ao leitor as novidades da terra. E nos espaços dedicados ao entretenimento do folhetim, jornalistas, literatos e novos escritores expressam suas opiniões e as mudanças ocorridas em todos os níveis sociais. A crônica, nesse período, constitui uma nova forma de dizer, em textos que tratavam dos hábitos e costumes dos brasileiros, daí a denominação crônica à brasileira, que significa esse discurso neste momento histórico. Segundo Joaquim Ferreira dos Santos (2005, p.16), “O jornal Espelho Diamantino produziu, a partir de 1828 , a pré-história da crônica ao manter uma seção fixa para registrar os usos e costumes do período". O mesmo é dito pela jornalista Cristiane Henriques Costa (2005, p. 247): "o jornal Espelho Diamantino lançou no Brasil a ideia de que todo jornal deveria contar com um observador de costumes, que registrasse o que visse e ouvisse em suas andanças pelas ruas da cidade". O estilo teria continuidade em outras publicações, pois, de acordo com Santos (2005, p.16), "O padre Lopes Gama em O Carapuceiro, em 1832, e Martins Pena, no Correio da Moda, em 1839, confirmaram a necessidade editorial de registrar, comentar com verve, como desse na telha, o que se via e ouvia nas ruas".

No entanto, esse período de transição não é considerado em muitas publicações sobre o gênero no Brasil. O período não é lembrado, por exemplo, por Luís Augusto Fischer em seu livro Literatura Brasileira - modos de usar. Para Fischer, o primeiro registro aconteceria décadas depois do surgimento da Imprensa Nacional: "o primeiro cronista parece que foi Francisco Otaviano de Almeida Rosa, no Jornal do Commercio do Rio de Janeiro, na precisa data de 2 de dezembro de 1852" (FISCHER, 2007, p. 50), ponto de vista também compartilhado por Coutinho (2003). De acordo com Grillo (2006, p.151):

O conhecimento dos gêneros é imprescindível para a inserção em um determinado campo de produção cultural. Entretanto, o processo social de atualização varia de campo para campo. Nas artes, as rupturas nos gêneros e a inversão hierárquica dos mesmos constituem uma aposta capaz de marcar época e fazer nomes de prestígio.

E quem marcou época foi José de Alencar; todos os autores citados anteriormente afirmam que foi Alencar que firmou o gênero nas páginas dos jornais. Segundo Santos, "foi a partir de 1854, quando José de Alencar publicou o primeiro folhetim da série "Ao 
correr da pena", no Correio Mercantil, que o gênero começou a ficar com o jeitão atual" (2005, p.16); e Coutinho escreve: "foi José de Alencar que imprimiu à crônica a mais alta categoria intelectual” (2003, p.124). Segundo Fischer, referindo-se a Alencar, "foi este o primeiro a alcançar excelência para seu texto no gênero" (2007, p. 51). Costa, por sua vez, escreve: "Joaquim Manuel de Macedo e José Alencar deram início a uma raça de cães vadios, livres farejadores do cotidiano, batizados com outro nome vale-tudo: crônica" (2005, p. 247).

A falta de precisão histórica, ou de um consenso entre os pesquisadores, sobre a origem do termo em terras brasileiras não nos parece difícil de entender; afinal, a crônica, nas primeiras décadas do século XIX, era um gênero discursivo novo, sendo constituído pelos discursos da história, do jornalismo e da literatura, que se entrecruzavam e teciam, aos poucos, o novo gênero: a crônica brasileira. Outro fator que dificulta a identificação do gênero pode estar ligada a sua autoria, pois na primeira metade do século XIX era escrita por jornalistas que não ganharam reconhecimento no campo literário. São os textos de José de Alencar, Francisco Otaviano de Almeida Rosa e Joaquim Manuel de Macedo que dão à crônica sentidos da esfera literária. Nesse ponto da análise, acreditamos ser importante retomar a noção de esfera/campo para entendermos que as palavras, expressões, proposições, podem mudar de sentido segundo as posições sustentadas por aqueles que as empregam; no caso José de Alencar, Francisco Otaviano Rosa e Joaquim Manuel de Macedo ocupavam lugares de destaque na produção dos jornais da época e eram considerados homens de letras. Esses autores entrelaçam gêneros primários e secundários para constituir a crônica brasileira, diferente da crônica à brasileira, como denomina Meyer. Em nosso entendimento, a pesquisadora, ao colocar o acento de crase em crônica à brasileira, marca esse período de transição, entre os anos de 1808 e 1950, quando o folhetim era definido por Meyer como espaço de vale-tudo:

suscita todas as formas e modalidades de diversão escrita: nele se contam piadas, se fala de crimes e monstros, se propõem charadas, se oferecem receitas de cozinha e beleza; aberto às novidades, nele se criticam as últimas peças, os livros recém saídos, o esboço do caderno B [...] (MEYER, 1992, p. 96).

Já com o termo crônica brasileira, queremos destacar quando o gênero já se mostra mais estabilizado, sendo reconhecido como enunciado diferenciado dos outros gêneros e narrativas, a partir, principalmente, das publicações de Alencar. No trecho recortado da crônica publicada em 24 de setembro de 1854, da série "Ao correr da pena", José de Alencar (2003, p. 29) explica como a crônica se realiza como discurso e gênero:

\footnotetext{
De um lado crítico, aliás de boa fé, é de opinião que o folhetinista inventou em vez de contar, o que por conseguinte excedeu os limites da crônica. Outro afirma que a plagiou, e prova imediatamente que se tal autor, se não disse a mesma coisa, teve intenção de dizer; porque enfim nihil sub sole novun. Se se trata de coisa séria, a amável leitora amarrota o jornal, e atira-o de lado com um momozinho displicente a que é impossível resistir. Quando se fala de bailes, de uma mocinha bonita, de uns olhos brejeiros, o velho tira os óculos de maçado e diz entre dentes: "Ah! O sujeitinho está namorando à minha custa! Não fala contra a reforma! Hei de suspender a assinatura".
} 
Alencar enuncia como se dá a formação do gênero crônica brasileira ao falar do ofício do folhetinista, e ao mesmo tempo marca o enunciado com a articulação dos gêneros primários, quando dá voz ao pai conservador, e secundários, quando da mobilização dos discursos histórico, literário e jornalístico, evidenciando a diferença discursiva relativamente à crônica à brasileira referida por Meyer. Outra diferença significativa para a constituição do novo gênero é o diálogo direto entre autor e leitor(a). $\mathrm{Na}$ crônica brasileira, Alencar e o/a leitor(a) estabelecem uma relação de proximidade, quase íntima, conversando tanto com as mulheres como com os homens, o que provoca um deslocamento ainda maior nas posições dialógicas, tanto de escritura como de leitura do gênero. Ao falar da mocinha, do pai e do pretendente, Alencar atrai a atenção dos diferentes leitores, colocando-os como protagonistas na cena enunciativa central da crônica. O/A leitor(a) consegue se ver nesse lugar criado, lhe é familiar. Machado de Assis, ao comentar a produção cronística de José de Alencar, escreveu: "curto era o espaço, pouca a matéria; mas a imaginação de Alencar supria ou alargava as coisas".2. A relação de proximidade com os/as leitores/as buscada por Alencar, segundo Nelson Werneck Sodré (1964), se dava com a colocação destes figurando nos romances como personagens fundamentais. Em nossa análise, identificamos a mesma estratégia adotada para os romances, nos textos cronísticos de Alencar, onde as personagens criadas para ilustrar a crônica são as mesmas buscadas para a leitura no folhetim/jornal.

\title{
4 A CRÔNICA - SUAS CONDIÇÕES DE PRODUÇÃO E SIGNIFICAÇÃO
}

Mesmo com tantas inovações enunciativas e sendo escrita por grandes escritores da literatura brasileira, à crônica não lhe foi garantida posição de grande gênero literário entre os literatos, conforme descreve Candido (1992, p.13):

\begin{abstract}
A crônica não é um gênero maior. Não se imagina uma literatura feita de grandes cronistas, que lhe dessem o brilho universal dos grandes romancistas, dramaturgos e poetas. Nem se pensaria em atribuir o Prêmio Nobel a um cronista, por melhor que fosse. Portanto, parece que a crônica é um gênero menor. Graças a Deus - seria o caso de dizer, porque sendo assim ela fica perto de nós.
\end{abstract}

A partir do dizer de Candido, podem-se levantar algumas hipóteses: o caráter de produto consumido e renovado a cada dia do papel jornal, por ser um gênero originário do rodapé do folhetim, por seu tamanho e relatar coisas do povo contribuíam, para essa visão, de alguns pesquisadores, de que a crônica era um gênero menor da literatura. Seu descarte, sua durabilidade, seu leitor afetavam essa significação. Segundo Sá (1997, p. 10):

\footnotetext{
2 Publicado como prefácio para uma edição d'O Guarani, da qual saíram apenas os primeiros fascículos, em 1887. Disponível em: <http://machado.mec.gov.br/images/stories/html/critica/mact35.htm>
} 
O jornal, portanto, nasce, envelhece e morre a cada 24 horas. Nesse contexto, a crônica assume essa transitoriedade, dirigindo-se a leitores apressados, que lêem nos pequenos intervalos da luta diária, no transporte ou no raro momento de trégua que a televisão lhes permite. Sua elaboração se prende a essa urgência: o cronista dispõe de pouco tempo para datilografar seu texto, criando-o, muitas vezes, na sala esfumaçada de uma redação. Mesmo quando trabalha no conforto e no silêncio de sua casa, ele é premido pela correria com que se faz um jornal, o que acontece mesmo com os suplementos semanais, sempre diagramados com certa antecedência.

Outro fator que pode ter contribuído para que a crônica fosse considerada gênero menor, por Candido e Sá, deve-se ao seu modo de funcionamento no jornal, que está ligado ao modo de produção do discurso jornalístico, compreendido aqui como o discurso que busca ordenar e organizar cotidianamente os acontecimentos, mostrando as diferentes versões dos fatos, mas nunca diferente do que foi relatado (MARIANI, 1998). O discurso jornalístico, por sua pressa em produzir e publicar novidades todos os dias, para muitos autores torna-se um discurso pouco afeito à forma, privilegiando apenas o conteúdo. Sua relevância (discurso jornalístico) é atribuída à busca do sentido de unidade e de uma "pretensa" verdade, ligado ao acontecimento histórico e à descrição dos fatos ou narração do ocorrido, e não propriamente por sua qualidade estética; por sua vez, no gênero crônica os sentidos ligados ao jornalismo e a seu modo de produção não impedem o cruzamento do discurso da literatura, entendido aqui como um discurso que, na contramão do discurso do jornalismo, trabalha o texto com toques poéticos, ficcionais ou dramáticos (CANDIDO, 1995), como encontramos nas crônicas de Rubem Braga, Nelson Rodrigues e Clarice Lispector, por exemplo. Ou seja, por ser um gênero híbrido, fica difícil enquadrá-lo, classificá-lo, fazê-lo pertencer a uma determinada esfera ou campo - uma vez que entendemos que as esferas dos discursos da história, do jornalismo e da literatura contribuem para sua constituição, conforme expressado na crônica de Artur da Távola:

\begin{abstract}
A literatura do jornal. O jornalismo da literatura. É a pausa da subjetividade, ao lado da objetividade da informação do restante do jornal. Um instante de reflexão, diante da opinião peremptória do editorial. [...] É, pois, a expressão jornalístico-literária da necessidade de não desistir de ser e sentir. A crônica é o samba da literatura (TÁVOLA, 2001).
\end{abstract}

A articulação discursiva entre as diferentes esferas parece exercer um fascínio nos cronistas, porque enquanto de um lado trabalha-se com o tempo, com o cotidiano que são marcas próprias dos discursos jornalístico e histórico, por outro lado mobiliza a fabulação da criação ficcional e poética do discurso da literatura. Assim, a crônica "discursiviza" o cotidiano e permite a possibilidade do equívoco ${ }^{3}$ (MEDEIROS, 2004). Uma fórmula tão tentadora que serviu de inspiração para Machado de Assis, escrever como se cria a crônica.

\begin{abstract}
Há um meio certo de começar a crônica por sua trivialidade. É dizer: Que calor! Que desenfreado calor! Diz-se isto agitando as pontas do lenço, bufando como um touro, ou simplesmente sacudindo a sobrecasaca. Resvala-se do calor aos fenômenos atmosféricos, fazem-se algumas conjeturas acerca do sol e da lua, outras sobre a febre amarela, manda-se um suspiro a Petrópolis, e La glace est rompue, está começada a crônica (ASSIS apud SANTOS, 2005, p. 27).
\end{abstract}

\footnotetext{
${ }^{3}$ Medeiros entende a crônica como um discurso que se constitui a partir de uma falha no ritual de sua produção.
} 
Machado de Assis mostra ao leitor, em $O$ nascimento da crônica, que o gênero privilegia o cotidiano; começa com uma conversa despretensiosa sobre o dia, temperada com expressões em francês, em um estilo que atinge o leitor mais exigente. Indo à frente no tempo, temos Rubem Braga, considerado por Bender como o maior cronista brasileiro, sendo reverenciado por ter um texto com fortes marcas poéticas. E, por meio da poesia, dos versos, repensa o fazer cronístico, na crônica $A$ traição das elegantes - $O$ mistério da poesia:

\begin{abstract}
Não sei o nome desse poeta, acho que boliviano; apenas lhe conheço um poema, ensinado por um amigo. E só guardei os primeiros versos; Trabajar era bueno en el Sur... Cortar los árboles, hacer canoas de los troncos. E tendo guardado esses dois versos tão simples, aqui me debruço ainda uma vez sobre o mistério da poesia. [...] Lembrei-me agora mesmo, no instante em que abri a máquina para trabalhar nessa coisa vã e cansativa que é fazer crônica. De onde vem o efeito poético? É fácil dizer que vem do sentido dos versos; mas não é apenas do sentido. [...] Isso me lembra um dos maiores versos de Camões, todo ele também com as palavras mais corriqueiras de nossa língua: "A grande dor das coisas que passaram." Talvez o que impressione seja mesmo isso: essa faculdade de dar um sentido solene e alto às palavras de todo dia. Nesse poema sul-americano a idéia da canoa é também um motivo de emoção (BRAGA, 2011, p. 347).
\end{abstract}

Braga escreve que a crônica é coisa vã e cansativa. Mas pensa no efeito poético. De onde vem? interroga-se. E, para reconsiderar a sentença, cita Camões. Dá-lhe gosto trabalhar com as palavras, com os sentidos. E a crônica permite este gesto, de estar cá e lá, da incerteza, da reflexão, do poético em coisas que parecem comuns, mas aos olhos dos cronistas transformam-se em matéria-prima de alta qualidade. Na crônica de Sabino o olhar no corriqueiro e a preocupação com a literalidade do texto são constitutivos do enunciado ("assim eu queria meu último poema"), em sua Última Crônica:

\begin{abstract}
A caminho de casa, entro num botequim da Gávea para tomar um café junto ao balcão. $\mathrm{Na}$ realidade, estou adiando o momento de escrever. A perspectiva me assusta. Gostaria de estar inspirado, de coroar com êxito mais um ano nessa busca do pitoresco ou do irrisório no cotidiano de cada um. Eu pretendia apenas recolher da vida diária algo de seu disperso conteúdo humano, fruto da convivência, que a faz mais digna de ser vivida. Visava ao circunstancial, ao episódico. Dessa perseguição do acidental, quer num flagrante de esquina, quer nas palavras de uma criança, ou num incidente doméstico, torno-me simples espectador e perco a noção do essencial. Sem nada mais para contar, curvo a cabeça e tomo meu café, enquanto o verso do poeta se repete na lembrança: "assim eu queria meu último poema". Não sou poeta e estou sem assunto. Lanço então um último olhar fora de mim, onde vivem os assuntos que merecem uma crônica (SABINO apud SANTOS, 2005, p. 188).
\end{abstract}

O texto marca a preocupação do autor com a composição, com o estilo e com o perene, "preocupações" mais ligadas ao discurso da literatura. Indo um pouco mais à frente, chegamos a Luis Fernando Veríssimo. O cronista exemplifica a relação entre autor e gênero, com a seguinte frase: "na verdade, a gente não escreve sobre a rotina, escreve sobre uma quebra de rotina, sobre coisas incomuns que acontecem com pessoas comuns e mudam suas vidas, alguma epifania ou paixão" (2008, p. 32). 
Machado de Assis, Rubem Braga, Fernando Sabino e Luis Fernando Veríssimo, mesmo com a distância do tempo, e de estilos, entre seus dizeres e produções, mantêm uma mesma compreensão com o gênero: privilegiar o diferente do dia a dia sem perder a graça do dizer. Essa relação com o acontecimento menor e o prosaico e, ao mesmo tempo, com o inusitado da vida do homem comum, serve de base para os cronistas desenvolverem seus textos. E esse seria o nó discursivo da crônica brasileira, entre a história, o jornalismo e a literatura, e que, segundo Candido, garantiria candidatura do gênero à perfeição.

\begin{abstract}
Por meio dos assuntos, da composição aparentemente solta, do ar de coisa sem necessidade que costuma assumir, ela se ajusta à sensibilidade de todo dia. Principalmente porque elabora uma linguagem que fala de perto ao nosso modo de ser mais natural. Na sua despretensão humanizada; e esta humanização lhe permite, como compensação, sorrateira, recuperar com a outra mão uma certa profundidade de significado e um certo acabamento de forma, que de repente podem fazer dela uma inesperada embora discreta candidata à perfeição (CANDIDO, 1992, p.13-14).
\end{abstract}

Candido caracteriza a crônica como gênero menor, mas ao mesmo tempo se desdobra em elogios para o gênero. Quem escreve crônica sabe desta condição, mas isso não impede ou impediu que o lugar do cronista, de observador do social, do homem comum que escreve com graça ao longo da história, fosse ocupado por grandes jornalistas/escritores, escritores/jornalistas, ou, como queiram chamar José de Alencar, Machado de Assis, Carlos Drummond de Andrade, João do Rio, Fernando Sabino, Tarsila do Amaral, Rubem Braga, Nelson Rodrigues, Luis Fernando Verissimo, Mario Prata, entre tantos outros que escreveram memoráveis histórias. Em seus afazeres, esses autores marcam a relação da crônica com as esferas discursivas, da história, do jornalismo e da literatura, e este pode ser um dos fatores que a fazem tão querida por seus leitores.

A intimidade, a história do cotidiano e a possibilidade de sentidos outros são transpostos às crônicas que atravessam décadas, sendo lidas e relidas por todas as gerações, publicadas em jornais de bairro ou de circulação nacional, em revistas, em livros e em antologias, mas que vivem sob o movimento da linguagem e do discurso. Assim, no final do século XX e início do século XXI as crônicas são adaptadas para os meios audiovisuais, publicadas em blogs, dando continuidade ao que lhes é constitutivo: permanecer em movimento, confrontando a história, o jornalismo e a literatura. Talvez o sentido da crônica brasileira seja este: causar o estranhamento, desestabilizar, fazer do incerto seu tempero mais genuíno e, em sua errância, buscando outros discursos para participar de sua trama. Agora sem o descarte do papel, na perenidade do mundo digital.

\title{
5 CONSIDERAÇÕES FINAIS
}

Neste artigo, analisamos como o gênero crônica histórica passa a funcionar como crônica brasileira no século XIX. Observamos como a cadeia de sentidos tramada pelos cronistas articulou os discursos da História, do Jornalismo e da Literatura para a constituição da crônica brasileira. A análise discursiva do gênero nos permitiu, ainda, observar como a posição do(a) leitor(a) do folhetim/jornal foi determinante para a realização do gênero. 
ALENCAR, J. de. Melhores crônicas. Direção de Edla van Steen; seleção de João Roberto Faria. São Paulo: Global, 2003.

BAKHTIN, M. Estética da criação verbal. Introdução e tradução do russo Paulo Bezerra; prefácio à edição francesa Tzvetan Todorov. 4. ed. São Paulo: Martins Fontes, 2003.

BENDER, F. C.; LAURITO, I. B. Crônica - história, teoria e prática. São Paulo: Scipione,1993.

BRAGA, R. 200 crônicas escolhidas. 18. ed. São Paulo: Record, 2011. Disponível em:

$<$ http://pt.scribd.com/doc/3102424/rubem-braga-200-cronicas-escolhidas>.

CANDIDO, A. et al. A crônica: o gênero, sua fixação e suas transformações no Brasil. Campinas, SP: Ed. da Unicamp; Rio de Janeiro: Fundação Casa de Rui Barbosa, 1992.

O direito à literatura. Vários escritos. 3. ed. São Paulo: Duas Cidades, 1995.

CASTRO, S. O descobrimento do Brasil. Porto Alegre: L\&PM, 2007.

COSTA, C. Pena de aluguel: escritores jornalistas no Brasil - 1904-2004, São Paulo: Companhia das Letras, 2005.

COUTINHO, A. A literatura no Brasil - Vol. III. Rio de Janeiro: São José, 1964.

. A literatura no Brasil. Vol. 6, Parte III - Relações e Perspectivas. Codireção Eduardo de Faria

Coutinho. 6. ed. São Paulo: Global, 2003.

FISCHER, L. A. Literatura Brasileira - modos de usar. Porto Alegre: L\&PM, 2007.

GRILLO, S. V. de C. Esfera e campo. In: BRAIT, B. (Org.). Bakhtin outros conceitos-chave. São Paulo: Contexto, 2006. p. 133-160.

LE GOFF, J. História e memória. Tradução de Bernardo Leitão. 5. ed. Campinas (SP): Ed. da Unicamp, 2003.

MARIANI, B. O PCB e a imprensa: os comunistas no imaginário dos jornais, 1922-1989. Rio de Janeiro: Revan; Campinas (SP): Ed. da Unicamp, 1998.

MACHADO, I. Gêneros discursivos. In: BRAIT, B. (Org.). Bakhtin conceitos-chave. São Paulo: Editora Contexto, 2005. p. 151-166.

MEDEIROS, V. G. de. Discurso cronístico: uma "falha no ritual” jornalístico. Linguagem em (Dis)curso, Tubarão, v. 5, n. 1, p. 93-118, jul./dez. 2004.

MELO, J. M. de. A crônica. In: CASTRO, G. de; GALENO, A. (Orgs.). Jornalismo e Literatura - A sedução da palavra. São Paulo: Escrituras, 2002.

MEYER, M. Voláteis e versáteis. De variedades e folhetins se fez a chronica. In: CANDIDO, A. et al. $A$ crônica: o gênero, sua fixação e suas transformações no Brasil. Campinas (SP): Ed. da Unicamp; Rio de Janeiro: Ed. Fundação Casa de Rui Barbosa, 1992. p. 93-134.

PÊCHEUX, M. Análise Automática do Discurso (AAD-69). In: GADET, F.; HAK, T. (Orgs.). Por uma análise automática do discurso: uma introdução à obra de Michel Pechêux. Tradução de Bethania S. Mariani [et al.]. 3. ed. Campinas (SP): Ed. da Unicamp, 1997. p. 61-161.

SÁ, J. de. A crônica. São Paulo: Ática, 1997.

SANTOS, J. F. dos. (Org. e Intr.). As cem melhores crônicas brasileiras. Rio de Janeiro: Objetiva, 2005. SODRÉ, N. W. História da literatura brasileira. 4. ed. Rio de Janeiro: Civilização Brasileira, 1964. TÁVOLA, A. Literatura de jornal (O que é a Crônica). Jornal O Dia, Rio de Janeiro, 27 jul. 2001. VERISSIMO, L. F. Entrevista à Caros Amigos, São Paulo, jan. 2008. 
Recebido em: 05/12/13. Aprovado em: 14/10/14.

Title: The Brazilian chronic woven by history, by the Journalism and Literature.

Author: Silvânia Siebert

Abstract: In this text, we analyze how the genre of the historical chronicle begins to function in the nineteenth century as a Brazilian chronic. Thus we analyze the chain of meanings that is constructed with the genre along its discursive course, focusing primarily on the discursive web of discourses of History, Journalism and of Literature. The theoretical perspective underlying this reflection is mainly based on readings of Bakhtin (2003), Grillo (2006), and Machado (2005) on genres, and Alencar (2003), Braga (2011), Coutinho (2003), Candido (1992), Meyer (1992), and Santos (2005), among others, on the chronicle and its functioning.

Keywords: Chronicle. Genre. Statement. History. Journalism. Literature.

Título: La crónica brasileña tejida por la história, por el periodismo y por la literatura Autor: Silvânia Siebert

Resumen: En este texto, buscamos analizar como el género crónica histórica pasa a funcionar como crónica brasileña desde el siglo XIX. Para eso, observamos la cadena de sentidos que se construye con el género a lo largo de su camino discursivo, con foco principalmente en la trama discursiva de los discursos de la Historia, del Periodismo y de la Literatura. La perspectiva teórica que basa esta reflexión parte, principalmente, de las lecturas de Bajtín (2003), Grillo (2006) y Machado (2005) sobre géneros discursivos, y de Alencar (2003), Braga (2011), Coutinho (2003), Candido (1992) Meyer (1992), Santos (2005), entre otros, sobre el género crónica y su funcionamiento.

Palabras-clave: Crónica. Género. Enunciado. Historia. Periodismo. Literatura. 